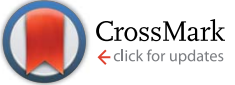

Cite this: RSC Adv., 2017, 7, 3617

\title{
Structures and properties of energetic cations in energetic salts
}

\begin{abstract}
W. Liu, ${ }^{a}$ W. L. Liu ${ }^{a}$ and S. P. Pang ${ }^{\star b}$
Energetic salts provide many advantages over conventional energetic molecular compounds. Their high densities, high heats of formation and low vapor pressures make them an important class of compounds for the development of energetic materials. More and more novel energetic ions are being obtained, but energetic cations are reported to a much lesser extent. Energetic cations develop from simple linear structures to form N-heterocyclic structures. Together with the introduction of various energetic groups, the energetic properties of energetic salts are significantly promoted. The development of energetic cations is becoming the major restriction for improving the performance of energetic salts.
\end{abstract}

Received 30th October 2016 Accepted 26th November 2016

DOI: $10.1039 / \mathrm{c} 6 \mathrm{ra2} 6032 \mathrm{~b}$

www.rsc.org/advances energetic groups can be introduced into the nitrogen-rich heterocyclic rings, which makes the compounds exhibit different acidities/alkalinities in becoming energetic cation/ anion substrates. Oxygen-rich groups (e.g. $-\mathrm{NO}_{2},-\mathrm{NHNO}_{2}$, $-\left(\mathrm{NO}_{2}\right)_{3}$ and $\left.-\mathrm{OH}\right)$ and high heats of formation groups (e.g. $\left.-\mathrm{N}_{3}\right)$ are electrophilic, whose introduction can turn the compounds into energetic anion bases, which could promote the oxidizing ability of the anions. While alkyl and amino groups (e.g. $-\mathrm{NH}_{2}$ ) are electron-rich, whose introduction can make the compounds energetic cation bases. Alkyl groups are useful for lowering melting points while amino groups are significant for lowering the sensitivities of energetic compounds. Therefore, energetic cations play important roles in determining the performance of energetic salts (Fig. 1). However, with a lack of oxygen in the substituted groups, energetic cations possess lower densities and worse oxygen balance than energetic anions. Meanwhile, compared with energetic anions, energetic cations are reported less frequently, and most energetic cations are amino-substituted

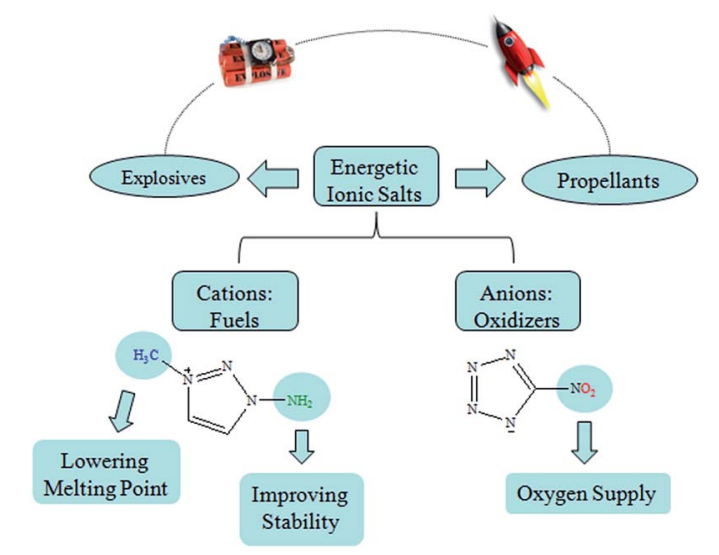

Fig. 1 The roles of cations and anions in energetic salts.

\footnotetext{
${ }^{a}$ Beijing Center for Physical and Chemical Analysis, Beijing Key Laboratory of Organic Materials Testing Technology \& Quality Evaluation, No. 7, Fengxian Central Road, Haidian District, Beijing, China. E-mail: liuwei@beijinglab.com.cn

${ }^{b}$ School of Materials Science \& Engineering, Beijing Institute of Technology, No. 5 South Street, Zhongguancun Haidian District, Beijing, China. E-mail: pangsp@bit. edu.cn; Fax: +86 010-68913038; Tel: +86 010-68913038
}

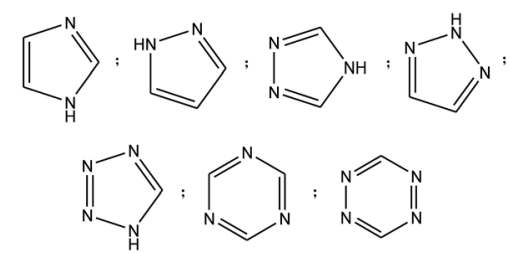

Scheme 1 The N-heterocyclic bases used for constructing energetic salts. 
or alkyl-substituted cations, which decrease the oxygen balance of the corresponding ionic salts. Density and oxygen balance are two important factors of energetic cations that restrict the promotion of energetic properties of the energetic salts.

Over the past few decades a large number of publications focusing on energetic salts have been reported. ${ }^{\mathbf{1 4 - 1 6}}$ Meanwhile, many novel energetic cations have also been reported. Research on energetic salts and liquids has been summarized in several reviews, but no review with the emphasis on energetic cations is currently available. Our continuing interest in energetic salts prompted us to review this unique field. In this review, energetic salts are discussed according to the backbones and substituted groups of the energetic cations, from 2002 to June 2016.

\section{Noncyclic cations-based ionic salts}

Ammonium, hydroxylammonium, hydrazinium, guanidinium and carbamide cations have been frequently used for the construction of energetic salts (Scheme 2), as they are easy to obtain. However, their simple structures only supply a few positions to modify, which limits the promotion of energetic performance of the ionic salts. Metal ions can also be used to construct ionic salts and have often been employed in primary explosives. The energetic performance of energetic salts based on metal ions has been studied to a less extent, therefore, the following review does not cover metal cations containing ionic salts.

In a number of publications regarding energetic salts, noncyclic cations were employed to cooperate with newly obtained energetic anions to produce target energetic salts. ${ }^{17-73}$ Among these noncyclic cations, ammonium possesses the simplest structure, and its energetic salts are very easy to obtain. Hydroxylammonium and carbamide derivatives are oxygen containing cations that are useful for the promotion of oxygen balance in ionic salts. Compared with carbamide derivatives, hydroxylammonium packing is more denser, therefore, energetic salts based on hydroxylammonium usually exhibit the best detonation properties. In addition, for poly-amino structures, energetic salts based on guanidinium usually possess the best thermal stabilities.

In 2015 , Forquet et al. ${ }^{74}$ reported a novel linear cation 2,2dimethyltriazanium through the reaction of 1,1-dimethylhydrazine with an aminating agent, which was used to obtain a series of energetic salts (Scheme 3). Some of the salts produced had an ionic liquid character with melting points below $100{ }^{\circ} \mathrm{C}$, which might be attributed to the dimethyl substitution. The sensitivities of the DMTZ salts towards impact

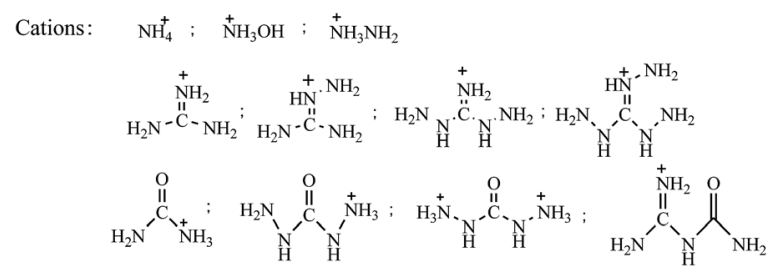

Scheme 2 Noncyclic energetic cations commonly used.

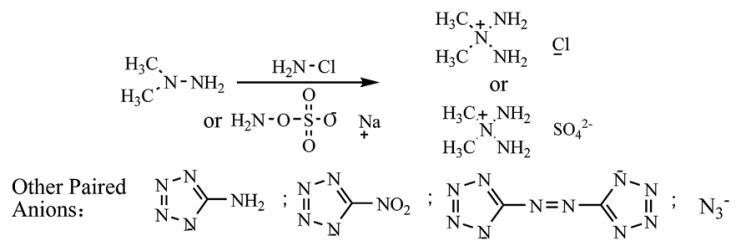

Scheme 3 Energetic salts based on 2,2-dimethyltriazanium.

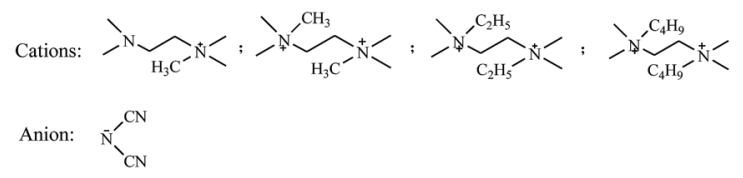

Scheme 4 Energetic salts based on tetramethylethylenediamine cations

and friction varied between insensitive and very sensitive, which could be explained in terms of hydrogen-bonding stabilization. However, their detonation properties were not studied.

Fei et $a .^{75}$ reported a selection of ionic liquids based on a tetramethylethylenediamine cation (Scheme 4). Though their detonation properties were much lower than those of TNT, the dicyanamide salt is hypergolic with $100 \% \mathrm{HNO}_{3}$ and exhibited potential as a green fuel for biopropellants.

\section{Monocyclic cations-based ionic salts}

Imidazole, pyrazole and triazole are five-membered heterocyclic compounds that exhibit weak alkalinities and can directly react with strong acids to form energetic salts. Amino and hydrazine groups can be introduced into heterocycles to enhance their alkalinity to form energetic cations. The heterocycles can also be used with alkylation reagents to produce energetic cations. In recent decades, various energetic salts based on fivemembered heterocyclic cations have been reported. Conversely, for six-membered N-heterocyclic ring compounds, such as triazine and tetrazine, energetic cations could only be obtained after being ionized through the introduction of electron-rich groups such as amino, hydrazine and so on. Energetic salts based on triazine and tetrazine cations have been less reported. In this review, energetic salts based on monocyclic cations were summarized by the differences in their substituted groups.

\subsection{Unsubstituted monocyclic cations-based ionic salts}

1,2,3-Triazole and 1,2,4-triazole show weak alkalinities and can react with strong acids directly to form energetic salts. Drake ${ }^{76}$ used 1,2,3-triazole and 1,2,4-triazole with nitric acid, perchloric acid and dinitramide to obtain a series of energetic salts (Scheme 5). The melting points of the energetic salts based on 1,2,4-triazolium were lower than the corresponding 1,2,3-triazolium analogues. In addition, the melting points of perchlorate 


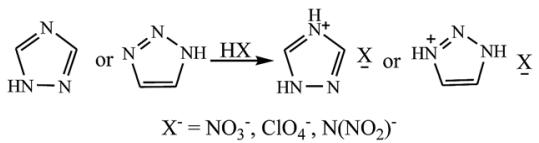

Scheme 5 Energetic salts based on unsubstituted triazolium.

and dinitramide were below $100{ }^{\circ} \mathrm{C}$, which is in the range of ionic liquids.

\subsection{Amino substituted monocyclic cation-based ionic salts}

The incorporation of amino groups into a heterocyclic triazole ring has been proven to be one of the simplest paths to enhancing thermal stability. ${ }^{77}$ Meanwhile, the $\mathrm{H}$ atoms in the amino group can form more hydrogen bonds, which can increase the tolerance ability of the compounds towards external impact and friction. Energetic salts based on amino substituted cations have been studied on a large scale, and the involved substrates including triazole, tetrazole, triazine and tetrazine, are discussed in detail in the following section.

3.2.1 Amino-substituted triazolium-based ionic salts. 1Amino-1,2,4-triazole and 4-amino-1,2,4-triazole can react with nitric acid, perchloric acid and dinitramide directly to form energetic salts. $^{78,79}$ The diamino-substituted compound 1,5diamino-1,2,4-triazole could also react with nitric acid and perchloric acid directly to form energetic salts (Scheme 6). In addition, 1-amino-1,2,4-triazole and 4-amino-1,2,4-triazole react with iodomethane can lead to the formation of quaternary salts, metathesis of which with various metal salts result in the corresponding energetic salts (Scheme 6). ${ }^{79}$

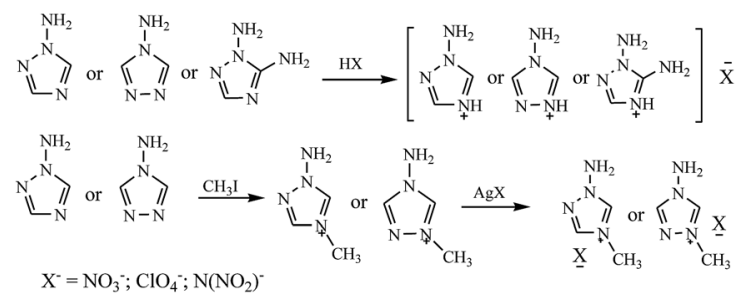

Scheme 6 Energetic salts based on amino-substituted 1,2,4triazolium

$$
\text { b: Cations: }
$$

Scheme 7 Energetic salts based on amino-substituted 1,2,3triazolium
Following the above methods, Drake et $a l .{ }^{\mathbf{8 0}}$ designed and synthesized a series of nitrate of alkyl-substituted 1-amino1,2,3-triazolium, involving alkyl groups including methyl, ethyl, $n$-propyl, allyl and $n$-butyl (Scheme 7a). The melting points of all nitrates were below $100{ }^{\circ} \mathrm{C}$, which is in the range of energetic ionic liquids. Based on the existing research, Lin et al. ${ }^{81}$ systematically produced a series of energetic salts based on 1-amino-1,2,3-triazolium and 1-amino-3-methyl-1,2,3triazolium (Scheme $7 \mathrm{~b}$ ), and their energetic properties were discussed in detail. For the same anion, energetic salts based on 1-amino-1,2,3-triazolium exhibited higher heats of formation and better detonation properties than the 1-amino-3-methyl1,2,3-triazolium analogues.

Guanidines were incorporated in 3-amino-1,2,4-triazole and 3,5-diamino-1,2,4-triazole to form a guanidine substituted 3amino-1,2,4-triazolate cation, which was combined with dinitramide to form energetic salts (Scheme 8). ${ }^{79}$

In $2015, \mathrm{Wu}$ et al. ${ }^{\mathbf{8 2 , 8 3}}$ prepared a series of energetic salts based on 3,4-diamino-1,2,4-triazolium (Scheme 9), and several salts exhibited useful thermal stabilities and low sensitivities towards impact as expected. In addition, most of these salts possess detonation properties comparable to those of TATB, which might be of interest for future applications as insensitive nitrogen-rich energetic materials.

Klapötke $^{10}$ processed the obtained 3,4,5-triamino-1,2,4triazole with iodomethane and combined it with an oxygen-rich anion to form a series of energetic salts (Scheme 10). The salts exhibited excellent thermal stability and low sensitivity, meaning they have potential used as high detonation energetic materials.

3.2.2 Amino-substituted tetrazolium-based ionic salts. Tetrazoles are five-membered heterocycles with four nitrogen

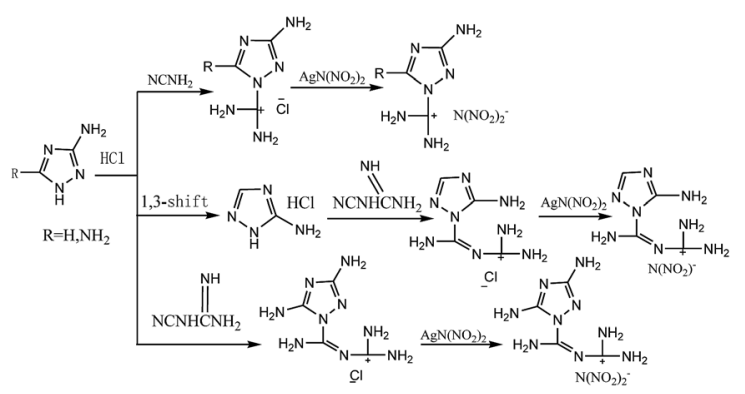

Scheme 8 Energetic salts based on guanidine- and aminosubstituted 1,2,4-triazolium

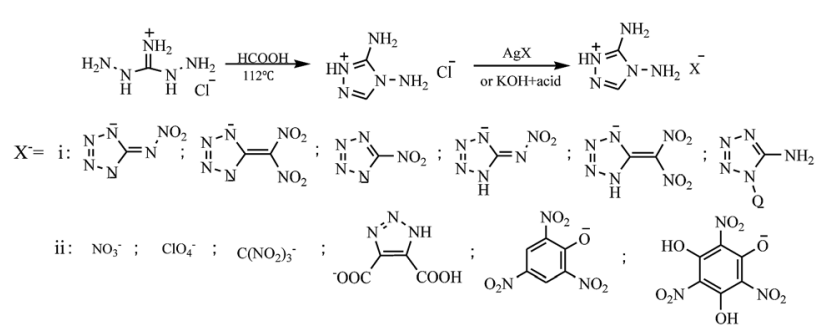

Scheme 9 Energetic salts based on diamino-substituted 1,2,4triazolium. 


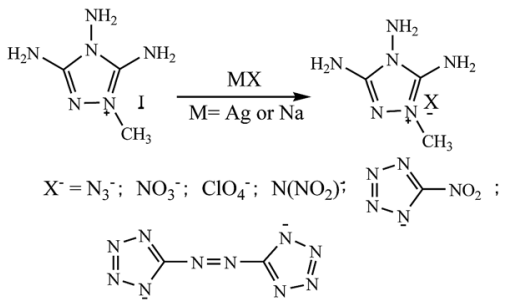

Scheme 10 Energetic salts based on poly-amino substituted 1,2,4triazolium.<smiles></smiles>

Scheme 11 Energetic salts based on amino substituted tetrazolium.

atoms in the ring. From 1,2,4-triazole $\left(+109.0 \mathrm{~kJ} \mathrm{~mol}^{-1}\right)$ to tetrazole $\left(237.2 \mathrm{~kJ} \mathrm{~mol}^{-1}\right)$, the heats of formation increase significantly. Energetic salts based on tetrazolium have been less frequently reported, with most studies referring to aminosubstituted tetrazolium.

Denffer et al. ${ }^{84}$ synthesized a 5 -aminotetrazolium nitrate (Scheme 11), whose detonation properties were computed through the Kamlet-Jacobs equation, with a detonation press at $35.7 \mathrm{GPa}$ and a detonation velocity at $8898 \mathrm{~m} \mathrm{~s}^{-1}$, higher than those of RDX, and close to those of HMX.

Methyl groups can be incorporated in 1-aminotetrazole and 2-aminotetrazole to construct energetic salts. Shreeve et al. ${ }^{78,85}$ reported the synthesis of nitrates and perchlorates based on dimethyl-substituted 1-aminotetrazole and 2-aminotetrazole (Scheme 12), which exhibited excellent thermal stabilities and could be applied as components of low signal propellants.

Klapötke et al. ${ }^{86}$ processed 1-methyl-5-aminotetrazole with iodomethane to achieve 1,4-dimethyl-5-aminotetrazolium iodate, the metathesis of which with silver 5-nitrotetrazolium to produce 1,4-dimethyl-5-amino-tetrazolium 5-nitrotetrazolate (Scheme 13). The obtained energetic ionic salt exhibited a safe energetic material, but its low detonation velocity, even lower than that of TNT, limited its application. Subsequently, Karaghiosoff $e t$ al. ${ }^{87}$ reported the synthesis of the nitrate, perchlorate, azide and dinitramide of 1,4-dimethyl-5-aminotetrazolium (Scheme 9), which all exhibited excellent thermal stabilities with decomposition temperatures mostly over $200{ }^{\circ} \mathrm{C}$. The impact sensitivities of the nitrate and dinitramide were over 30 $\mathrm{J}$, but the perchlorate was sensitive to impact. Meanwhile,

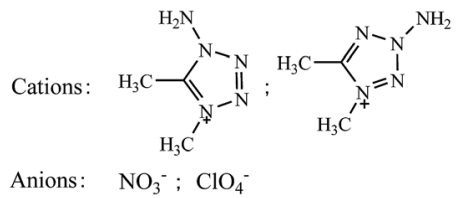

Scheme 12 Energetic salts based on dimethyl substituted aminotetrazolium.

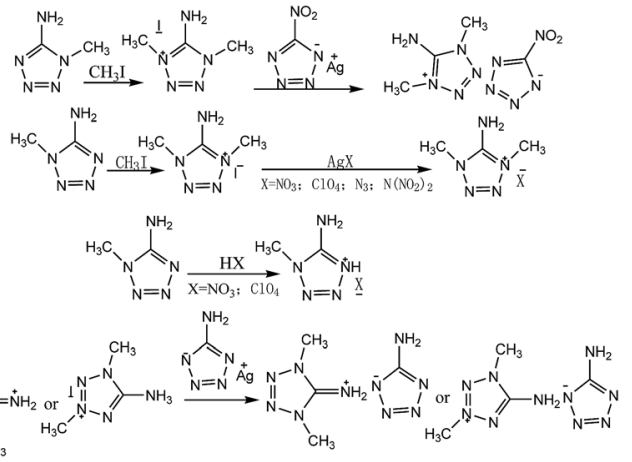

Scheme 13 Energetic salts based on dimethyl-substituted 5aminotetrazolium.

another nitrate and perchlorate were obtained through the direct acidification of nitric and perchloric acids.

Klapötke et al. ${ }^{88}$ reacted 1-methyl-5-aminotetrazole with iodomethane, resulting in the formation of two isomeric cations, which were combined with 5-aminotetrazolium to form the corresponding energetic salts (Scheme 13). Both the obtained energetic salts exhibited decomposition temperature over $200{ }^{\circ} \mathrm{C}$ and insensitivities towards both impact and friction. Their detonation velocities were at about $8000 \mathrm{~m} \mathrm{~s}^{-1}$, higher than that of TNT, meaning they could be used as insensitive energetic materials.

In 2009, Klapötke et $a l^{89}$ not only reported the synthesis of energetic salts based on 5-aminotetrazolium and 1-methyl-5aminotetrazolium, but also obtained novel silver substituted 5 -aminotetrazolium derivative cations (Scheme 14). The energetic salts based on silver substituted cations were extremely sensitive, but they were more environmental friendly than lea$\mathrm{d}(\mathrm{II})$ diazide in initiation devices for civil and military applications.

The hydrogen atom of 5-aminotetrazole can be substituted by another amino group to form 1,5-diaminotetrazole, which could undergo acidification or methylation into energetic cations that can be used to construct energetic salts. Klapötke et al. ${ }^{90}$ first obtained 1,5-diamino-4-methyltetrazolium iodate through the methylation of 1,5-diaminotetrazole. Subsequently, 1,5-diamino-

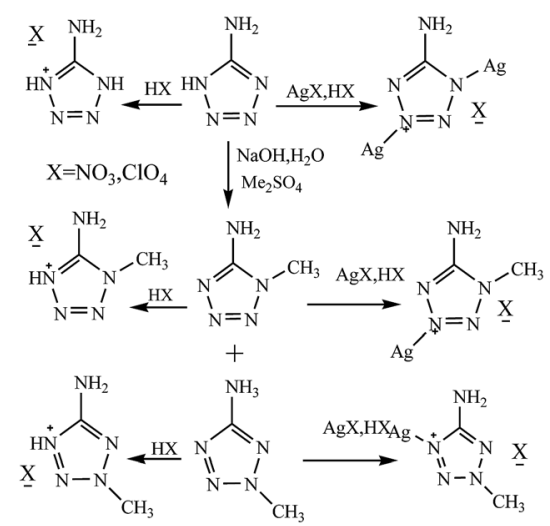

Scheme 14 Energetic salts based on silver substituted 5aminotetrazolium. 
4-methyltetrazolium dinitramide was obtained through metathesis (Scheme 15). Later on, Klapötke et al. ${ }^{91}$ reported a safer path to synthesizing 1,5-diamino-4-methyltetrazolium 5-nitrotetrazolate (Scheme 14), but its detonation property was just comparable to that of TNT. Following the same methods, Ruiz et $a .^{92}$ synthesized other energetic salts of 1,5-diamino-4methyltetrazolium, including a nitrate, a dinitramide and an azide (Scheme 15), whose detonation properties were calculated through the Kamlet-Jacobs equation. The detonation velocities of the nitrate and dinitramide were both comparable to that of RDX, while the nitrate was insensitive to impact $(>40 \mathrm{~J})$, but other salts were sensitive to impact. In addition, Ruiz et al. obtained the nitrate and perchlorate of 1,5-diaminotetrazolium through the acidification of nitric acid and perchloric acid, respectively. Tao et al. ${ }^{93}$ obtained other oxygen-rich salts of 1,5-diaminotetrazolium through acidification directly, including 5-nitrotetrazolate, 3,5dinitro-1,2,4-triazolate and 2,4,5-trinitroimidazolate (Scheme 15). These three oxygen-rich salts all exhibited thermal stability with decomposition temperatures over $180{ }^{\circ} \mathrm{C}$.

In 2012, Klapötke et al. ${ }^{94}$ obtained the first tetrazolium cation containing three amino groups on the same tetrazole ring through the amination of the neutral tetrazole species $(1,5-$ diaminotetrazole) (Scheme 16). The target cation, 1,4,5-triaminotetrazolium, at over $84 \%$ nitrogen extends its use in explosive materials as well as propellant formulations. Meanwhile, its energetic salt nitrate and nitrotetrazolate 2-oxide were synthesized and fully characterized. The two salts possessed moderate densities of $1.663 \mathrm{~g} \mathrm{~cm}^{-3}$ and $1.710 \mathrm{~g} \mathrm{~cm}^{-3}$, respectively. Their detonation properties were comparable to those of RDX. Their low thermal stabilities prevent them from being practical energetic materials; however, the study did indicate that there is a limit to the thermal stability as heats of formation and the associated nitrogen content increase.

3.2.3 Amino-substituted triazine cation-based ionic salts. 1,3,5-Triazine possesses a high density, a high heat of formation

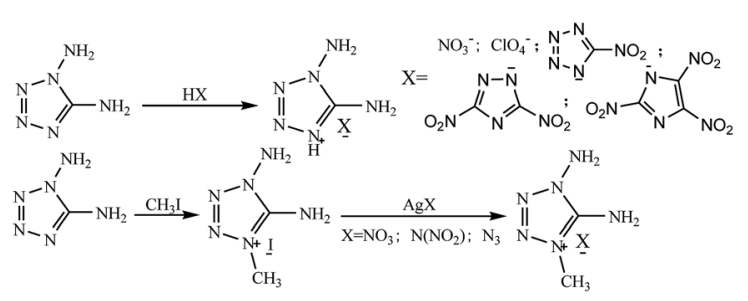

Scheme 15 Energetic salts based on 1,5-diaminotetrazolium and its derivatives.

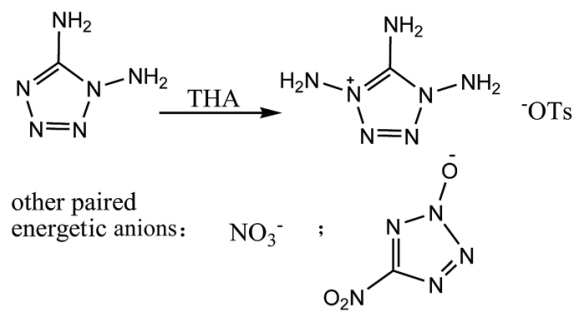

Scheme 16 Energetic salts based on 1,4,5-triaminotetrazolium. and excellent thermal stability, and is important precursor for the synthesis of energetic materials. 1,3,5-Triazine has three positions for modification, therefore various energetic groups such as amino and nitroamino groups can be incorporated in the triazine ring to construct energetic backbones. The hydrogen atoms of 1,3,5-triazine can all be substituted by amino groups to form 2,4,6-triamino-1,3,5-triazine, which is an excellent backbone for constructing energetic materials. Mostly research on triazine is based on triazine anions. Shreeve et al. ${ }^{36}$ and Srinivas et $a l .{ }^{56}$ reported two salts based on a 2,4,6-triamino1,3,5-triazine cation (Scheme 17a). Both showed excellent thermal stabilities with decomposition temperatures at about $300{ }^{\circ} \mathrm{C}$, and were not sensitive towards impact (IS $>40 \mathrm{~J}$ ). Based on the obtained triazine energetic cation, first discovered in the 1930 s, the author a reported series of energetic salts based on the first triazine energetic cation (Scheme 17b). The novel oxygen-containing triazine cation was the first oxygenincorporated heterocyclic cation, which improved the oxygen balance of the energetic cation. Those obtained energetic salts exhibited excellent thermal stabilities and safety, while some of them possessed detonation properties comparable to TATB, meaning they could be potential substitutes for TATB.

\subsection{Alkyl-substituted monocyclic cation-based ionic salts}

The incorporation of methyl groups into heterocycle compounds can lower the melting points of the compounds, especially for imidazole compounds, which can be used as energetic cations to synthesize energetic ionic liquids. In 2004, Ogihara et al. ${ }^{95}$ combined 1-ethyl-3-methyl-imidazolium with 1,2,4-triazolate and tetrazolate (Scheme 18) separately, to synthesize the corresponding energetic ionic liquids. In 2005, Katritzky et al. ${ }^{96}$ combined 1-butyl-3-methyl-imidazolium with

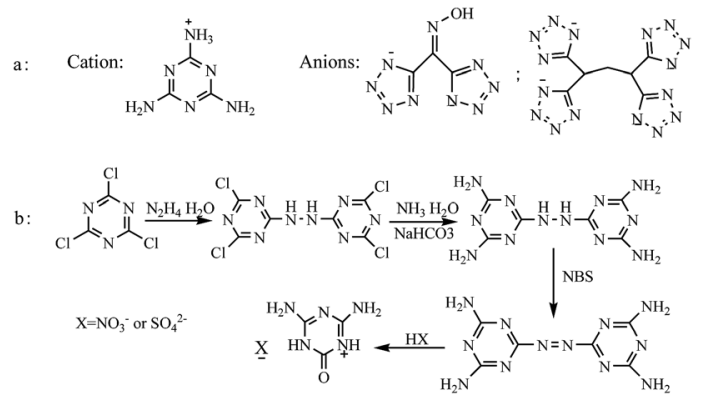

Scheme 17 Energetic salts based on amino-substituted triazine cations.

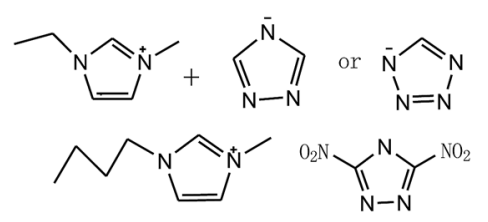

Scheme 18 Energetic salts based on methyl-substituted imidazolium. 


$$
\begin{array}{ll}
\mathrm{R}_{1}=\mathrm{CH}_{3}, \mathrm{CH}_{3} \mathrm{CH}_{2}, \mathrm{H} ; \quad \mathrm{R}_{2}=\mathrm{H}, \mathrm{CH}_{3}, \mathrm{~N}_{3} ; \\
\mathrm{R}_{3}=\mathrm{CH}_{3}, \mathrm{H} ; \quad \mathrm{NO}_{2}, \mathrm{H} ;
\end{array}
$$

Scheme 19 Energetic salts based on nitro or azide substituted imidazolium.

rigid 3,5-dinitro-1,2,4-triazolate to produce a novel energetic ionic liquid (Scheme 16) that exhibited very low melting point.

Xue et al. ${ }^{97}$ incorporated nitro or azide into imidazole to produce an energetic cation, which was combined with the nitrate or perchlorate to obtain the corresponding energetic salts (Scheme 19). These energetic salts exhibited relatively high melting points, and the melting point of the nitrate was lower than that of the perchlorate.

The incorporation of azido groups into the triazole ring can greatly increase the heat of formation, but at the same time it decreases the safety of the compound. The heat of formation of 1,2,4-triazole is $109 \mathrm{~kJ} \mathrm{~mol}^{-1}$, which increase to $458 \mathrm{~kJ} \mathrm{~mol}^{-1}$ after the incorporation of azido, with the sensitivity of the azido substituted triazole also increasing significantly. The azidosubstituted triazoles react with nitric acid or perchloric acid directly to form energetic salts (Scheme 20). ${ }^{\mathbf{8 5}, 97}$ The azidosubstituted triazole could also undergo methylation by iodomethane to form an energetic cation, which could be used to construct energetic salts through metathesis. ${ }^{97}$

The processing of a fluoroalkyl-substituted ethyl acetate derivative with hydrazine hydrate produces a fluoroalkyl substituted 1,2,4-triazole, which could be methylated to form fluoroalkyl-substituted 1,2,4-triazolium cation. Following this method, Xue et al. ${ }^{98}$ designed and synthesized a series of energetic salts based on a fluoroalkyl-substituted 1,2,4-triazolium cation (Scheme 21a). And if fluorine containing methylation
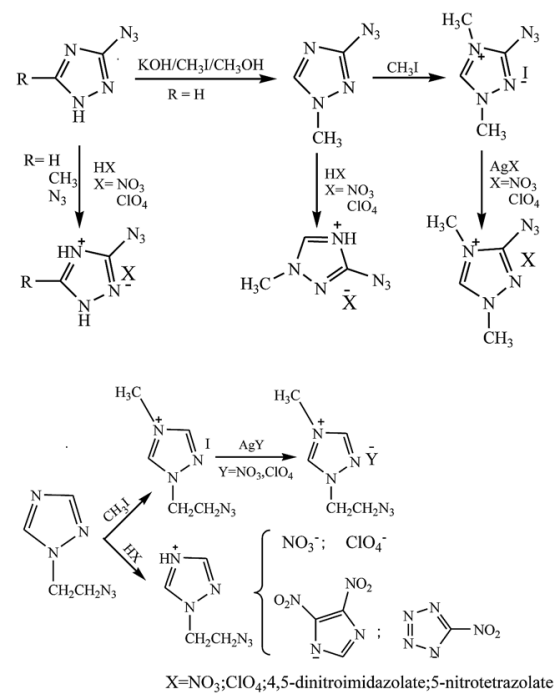

Scheme 20 Energetic salts based on azido-substituted triazolium.

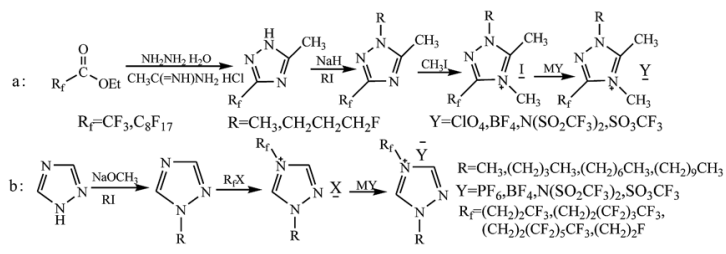

Scheme 21 Energetic salts based on fluoroalkyl-substituted triazolium.

reagent is involved in the ionization, the fluoroalkyl substituted energetic cation could also be produced. Based on this method, Mirazei et $a{ }^{99}{ }^{99}$ synthesized another series of energetic salts based on the fluoroalkyl-substituted 1,2,4-triazolium cation (Scheme 21b). The introduction of fluorine in the substituted groups increases the densities of the energetic salts, and the densities would increase as the content of fluorine or the numbers of fluoroalkyl added.

Gao et al. ${ }^{100}$ processed 4-amino-1,2,4-triazole with a $\mathrm{SF}_{5}$ containing methylation reagent, and the $\mathrm{SF}_{5}$ containing alkyl substituted 4-amino-1,2,4-triazolium cation was obtained, metathesis of which with metal salts was used to produce series of energetic salts (Scheme 22). The obtained energetic salts exhibited low melting points, lying in the range found for energetic ionic liquids.

Romero $^{\mathbf{1 0 1}}$ reported new energetic ionic liquids derived from metronidazole (Scheme 23). The obtained cation contained some oxygen-rich substituted groups $\left(-\mathrm{NO}_{2}\right.$ and $\left.-\mathrm{ONO}_{2}\right)$, which are useful for improving the oxygen balance of energetic salts. The synthesized energetic salts exhibited good thermal stabilities with decomposition temperatures ranging from 144.0 to 192.8 ${ }^{\circ} \mathrm{C}$, but their detonation properties were not studied.

\subsection{Hydrazine-substituted monocyclic cation-based ionic salts}

Hydrazine cations are commonly used in the construction of energetic salts, but energetic salts based on hydrazinesubstituted monocyclic cation are reported less frequently.

Wu et al. ${ }^{\mathbf{1 0 2}}$ processed amino-, hydrazino- and mercaptosubstituted 1,2,4-triazole with nitrate acid or perchloric acid

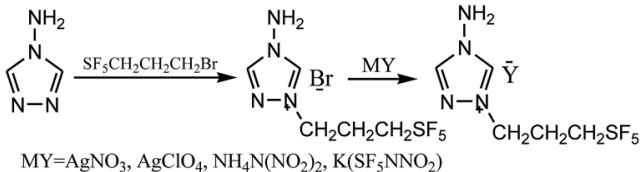

Scheme 22 Energetic salts based on $\mathrm{SF}_{5}$ containing alkyl-substituted triazolium.

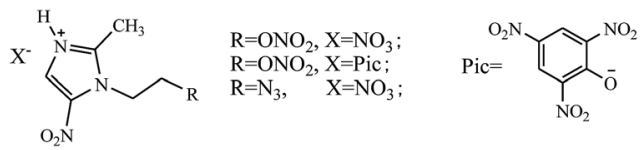

Scheme 23 Energetic salts derived from metronidazole. 


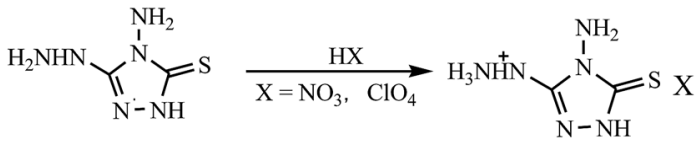

Scheme 24 Energetic salts based on hydrazine-substituted triazolium.

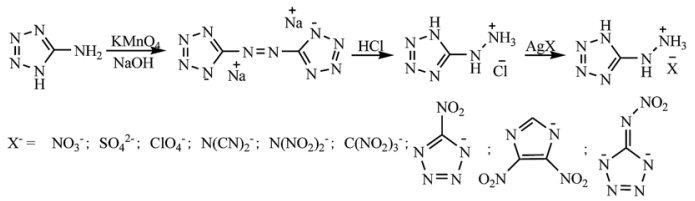

Scheme 25 Energetic salts based on hydrazine-substituted tetrazolium.

directly, and the corresponding energetic salts were obtained (Scheme 24), but their energetic properties were not studied.

Based on the obtained $5,5^{\prime}$-azobis-tetrazole, we treated it with chlorate acid, and 5-hydrazine tetrazolium chlorate was produced, metathesis of which with various metal salts resulted in a series of energetic salts (Scheme 25). ${ }^{103}$ These salts possess relatively high densities, in which perchlorate reach as high as $2.068 \mathrm{~g} \mathrm{~cm}^{-3}$; meanwhile, these salts exhibited excellent thermal stabilities, with decomposition temperatures all above $150{ }^{\circ} \mathrm{C}$. In addition, their detonation properties are comparable to those of HMX and these salts exhibited moderate impact sensitivities (10 J), meaning they have wide application prospects.

Hydrazine could also be incorporated with tetrazine to form energetic cations, which were paired with the obtained novel anions to produce energetic salts (Scheme 26) ${ }^{48,49,55}$ These salts exhibited relatively high densities (above $1.80 \mathrm{~g} \mathrm{~cm}^{-3}$ ) and detonation properties comparable to that of RDX.

Recently, Wu et al. ${ }^{104}$ reported a new series of energetic salts based on 3-hydeazino-4-amino-1,2,4-triazolium (Scheme 27). The obtained salts exhibited relatively high densities ranging from 1.649 to $1.858 \mathrm{~g} \mathrm{~cm}^{-3}$ and excellent thermal stabilities with decomposition temperatures ranging from 168 to $266^{\circ} \mathrm{C}$.<smiles>[NH3+]Nc1nnc(N[15NH2])nn1</smiles>

Scheme 26 Energetic cation of hydrazinium-substituted tetrazine.

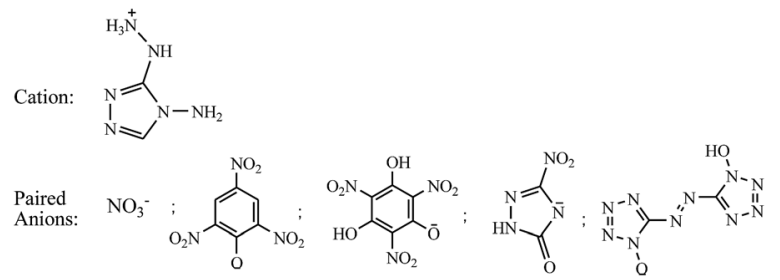

Scheme 27 Energetic salts based on 3-hydrazino-4-amino-1,2,4triazolium
However, most of their detonation properties were lower than those of TATB, which might limit their application.

\subsection{Guanidine-substituted monocyclic cations-based ionic salts}

Guanidine is a thermally stable group with high nitrogen content, therefore, the introduction of guanidine groups into tetrazine could improve the nitrogen content and thermal stability. The 3,6-diguanidine-1,2,4,5-tetrazine cation is an excellent energetic ionic ligand, which is widely used in constructing energetic salts (Scheme 28). ${ }^{17,21,28,29,46,49,53}$ Most of these salts show excellent thermal stabilities, but their densities are mostly not very high.

As for the feature of electron-withdrawing inductive effects from the nitro groups, almost all the compounds containing polynitro groups act as anions. Wu et al. ${ }^{105}$ reported a novel cation containing guanidinium group as well as a picryl moiety, upon which a series of energetic salts were synthesized (Scheme 29). All the energetic salts exhibited excellent thermal stabilities, most over $180{ }^{\circ} \mathrm{C}$, meanwhile, these salts performed sustainable sensitivities towards impact, friction and electrostatic discharge. Moreover, these salts possessed detonation properties comparable to those of TATB, which made them promising candidates for energetic materials.

Recently, Klapötke et al. ${ }^{106}$ created other salts based on guanidinium-substituted polynitroarene (Scheme 30 ). These salts all exhibited excellent thermal stabilities with decomposition

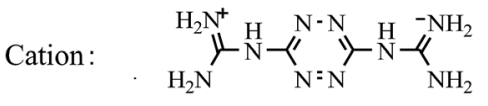

Scheme 28 Energetic cation of guanidinium-substituted tetrazine.

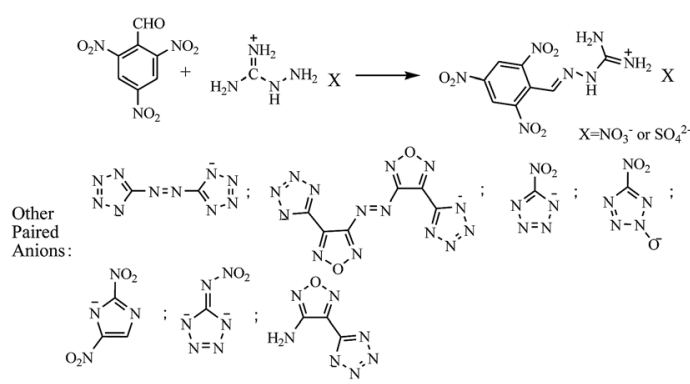

Scheme 29 Energetic salts based on guanidinium-substituted polynitroarene.

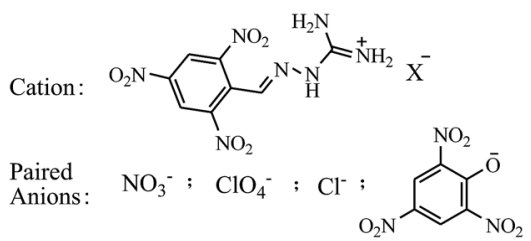

Scheme 30 Other energetic salts based on guanidinium-substituted polynitroarene. 
temperatures over $200{ }^{\circ} \mathrm{C}$. But their detonation properties were only comparable to those of TNT, which might limit their potential application.

\section{Dicyclic and polycyclic cations- based ionic salts}

Compared with monocyclic cations, bridged polycyclic cations lay denser and possess higher nitrogen contents, which are useful for improving the energetic performance.

Gao et al. ${ }^{107}$ obtained $\mathrm{C}-\mathrm{N}$ bridged imidazole and triazole or tetrazole cations through the processing of methylsulfonyl and nitro-substituted imidazole, which were paired with nitric or perchlorate to produce a series of energetic salts (Scheme 31). The obtained energetic salts exhibited excellent thermal stabilities and moderate densities, but their detonation properties were not studied.

A $\mathrm{N}-\mathrm{N}$ bridge dicyclic cation has been reported. In 2005, Shreeve et al. ${ }^{108}$ reported the synthesis of 4,4-bis-1,2,4-triazole, which was processed with nitric acid and perchlorate acid, respectively, and corresponding energetic salts were obtained. Additionally, they reported another dicyclic cation, $N$-4-(1,2,4triazole)- $N$-3-(4-methyl-1,2,4-triazolium)amine, and obtained its nitrate, perchlorate and 5-nitro-tetrazolate (Scheme 32). For the obtained energetic salts, perchlorate exhibited the best thermal stability and the highest density.

Recently, Klapötke et al. ${ }^{\mathbf{1 0 9}}$ designed and synthesized series of poly-nitrogen and oxygen-rich energetic salts 5,5'-bis-(3,4diamino-1,2,4-triazolium) cation (Scheme 33), which exhibited relatively high densities ranging from 1.65 to $1.87 \mathrm{~g} \mathrm{~cm}^{-3}$. All these energetic salts decomposed over $200{ }^{\circ} \mathrm{C}$ except for the nitroformate salt. In addition, these energetic salts showed excellent detonation properties, with detonation velocities ranging from 8051 to $9053 \mathrm{~m} \mathrm{~s}^{-1}$, detonation pressures ranging from 22.1 to $34.3 \mathrm{kPa}$. However, the high sensitivities towards impact $(<10 \mathrm{~J})$ limited their potential application.

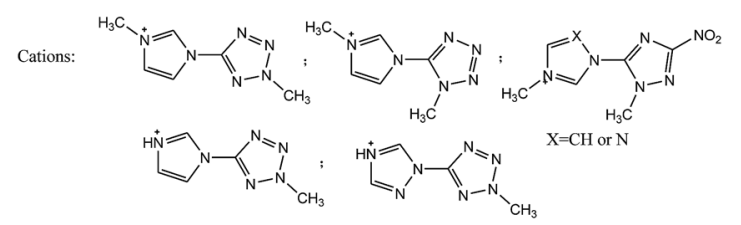

Scheme 31 Energetic salts based on $\mathrm{C}-\mathrm{N}$ bridged energetic dicyclic cations.

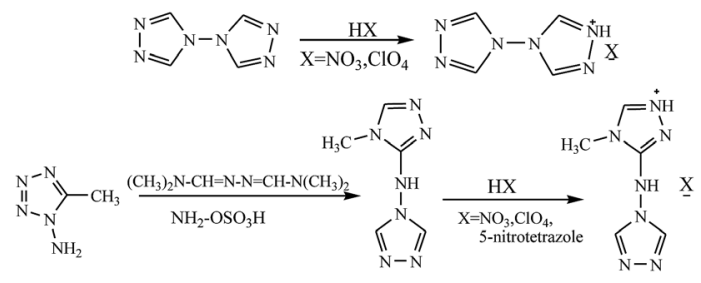

Scheme 32 The $\mathrm{N}-\mathrm{N}$ bridged energetic cation.

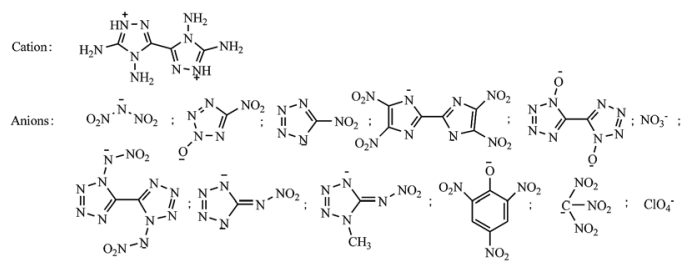

Scheme 33 Energetic salts based on C-C bridged energetic dicyclic cation.

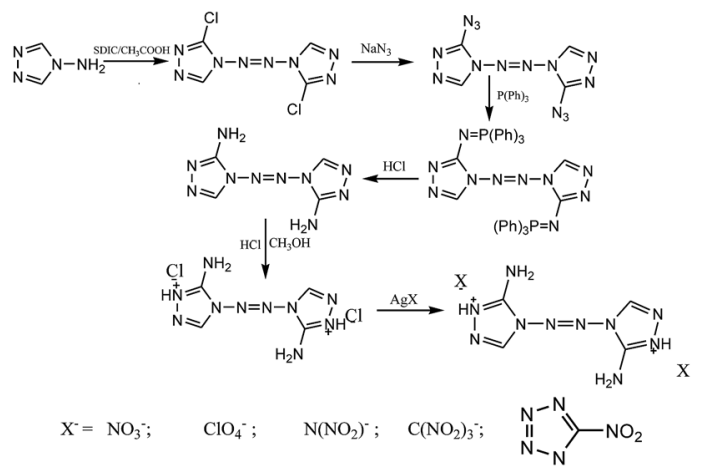

Scheme 34 Energetic salts based on azo-bridged energetic dicyclic cation.

In the previous study, the introduction of azo group has been proven to be an effective path to improving the densities and heats of formation. ${ }^{\mathbf{1 1 0}}$ To achieve high performance energetic salts, the author synthesized a series of energetic salts based on the azo group bridged dicyclic cation, 3,3'-diamino-4,4'-azo1,2,4-triazolium (Scheme 34). ${ }^{\mathbf{1 1 1}}$ All the obtained energetic salts exhibited high thermal stabilities with decomposition temperatures over $200{ }^{\circ} \mathrm{C}$ except for the nitroformate. These energetic salts showed relatively high densities ranging from 1.71 to $1.99 \mathrm{~g} \mathrm{~cm}^{-3}$. Meanwhile, these energetic salts exhibited moderate sensitivities and excellent detonation properties, some even higher than those of HMX, making them potential substitutes for HMX.

\section{Conclusions}

In the pursuit of high performance energetic salts, large amounts of novel structured energetic anions/cations have been reported. However, energetic cations are reported on a lesser scale, and the reported energetic cations often possess poor oxygen balance, which become the primary limitation to promoting the energetic properties of energetic salts.

From simple linear structures to N-heterocyclic structures, plenty of novel energetic cations have been reported (Fig. 2). Simultaneously, a significant number of high performance energetic salts have been obtained. For the linear cations, they pack denser energetic salts, which usually possess higher densities; however, their simple structures supply less space for modification. As for the monocyclic cations, the N-heterocyclic structure provide higher heats of formation than the linear 


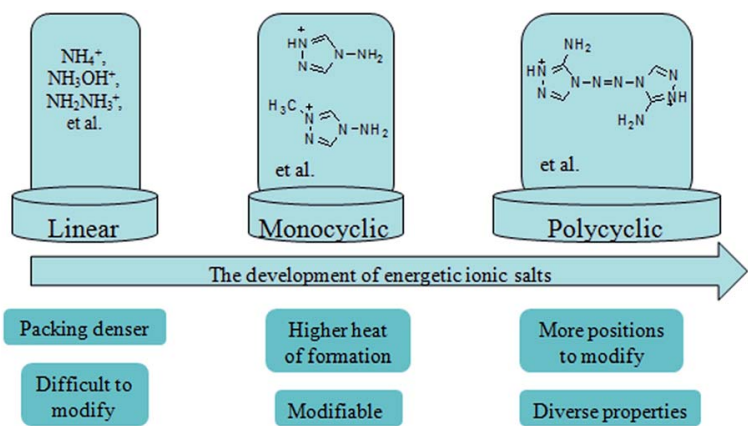

Fig. 2 Development of energetic cations in the research of energetic salts.

structure, while the heterocyclic structure supplies positions for modification, which could improve the energetic properties of energetic salts. Compared with the monocyclic structure, the polycyclic backbones provide more positions to modify, which provide more space for the improvement of energetic performance. With the introduction of various kinds of energetic groups into the polycyclic structures, more and more novel and excellent energetic cations would be obtained in future, which would improve the energetic performance of energetic salts.

\section{Acknowledgements}

The authors gratefully acknowledge the support of the National Natural Science Foundation of China (21576026) and the opening project of Beijing Academy of Science and Technology Specific Financial Funds (No. PXM2016_178305_000010).

\section{Notes and references}

1 V. Thottempudi, P. Yin, J. H. Zhang, D. A. Parrish and J. M. Shreeve, Chem.-Eur. J., 2014, 20, 542.

2 A. A. Dippold and T. M. Klapötke, J. Am. Chem. Soc., 2013, 135, 9931.

3 T. M. Klapötke, N. Mayr, J. Stierstorfer and M. Weyrauther, Chem.-Eur. J., 2014, 20, 1410.

4 N. Kommu, V. D. Ghule, A. S. Kumar and A. K. Sahoo, Chem.-Asian J., 2014, 9, 166.

5 Z. Q. Wang, D. Jishkariani, B. J. Killian, I. Ghiviriga, C. D. Hall, P. J. Steel and A. R. Katritzky, J. Energ. Mater., 2014, 32, 227.

6 Q. H. Zhang, C. L. He, P. Yin and J. M. Shreeve, Chem.-Asian J., 2014, 9, 212.

7 D. E. Chavez, S. K. Hanson, J. M. Veauthier and D. A. Parrish, Angew. Chem., Int. Ed., 2013, 52, 6876.

8 Q. Wu, W. H. Zhu and H. M. Xiao, J. Mater. Chem. A, 2014, 2, 13006.

9 R. P. Singh, R. D. Verma, D. T. Meshri and J. M. Shreeve, Angew. Chem., Int. Ed., 2006, 45, 3584.

10 C. Darwich, T. M. Klapötke and C. M. Sabaté, Chem.-Eur. J., 2008, 14, 5756.

11 R. H. Wang, H. Y. Xu, Y. Guo, R. J. Sa and J. M. Shreeve, J. Am. Chem. Soc., 2010, 132, 11904.
12 V. Thottempudi and J. M. Shreeve, J. Am. Chem. Soc., 2011, 133, 19982.

13 T. Fendt, N. Fisher, T. M. Klapotke and J. Stierstorfer, Inorg. Chem., 2011, 50, 1447.

14 R. P. Singh, R. D. Verma, D. T. Meshri and J. M. Shreeve, Angew. Chem., Int. Ed., 2006, 45, 3584.

15 H. X. Gao and J. M. Shreeve, Chem. Rev., 2011, 111, 7377.

16 Q. H. Zhang and J. M. Shreeve, Chem. Rev., 2014, 114, 10527.

17 Y. Q. Zhang, Y. Guo, Y. H. Joo, D. A. Parrish and J. M. Shreeve, Chem.-Eur. J., 2010, 16, 10778.

18 Y. Q. Zhang, Y. G. Huang, D. A. Parrish and J. M. Shreeve, J. Mater. Chem., 2011, 21, 6891.

19 Y. Q. Zhang, D. A. Parrish and J. M. Shreeve, Chem.-Eur. J., 2012, 18, 9987.

20 M. J. Crawford, K. Karaghiosoff, T. M. Klapötke and F. A. Martin, Inorg. Chem., 2009, 48, 1731.

21 V. Thottempudi and J. M. Shreeve, J. Am. Chem. Soc., 2011, 133, 19982.

22 T. M. Klapötke, M. Stein and J. Stierstofer, Z. Anorg. Allg. Chem., 2008, 634, 1711.

23 T. M. Klapötke, P. Mayer, C. M. Sabaté, J. M. Selch and N. Wiegand, Inorg. Chem., 2008, 47, 6014.

24 M. Göbel, K. Karaghiosoff, T. M. Klapötke, D. G. Piercey and J. Stierstorfer, J. Am. Chem. Soc., 2010, 132, 17216.

25 T. M. Klapötke and J. Stierstorfer, J. Am. Chem. Soc., 2009, 131, 1122.

26 T. M. Klapötke, D. G. Piercey and J. Stierstorfer, Chem.-Eur. J., 2011, 17, 13068.

27 R. Haiges and K. O. Christe, Inorg. Chem., 2013, 52, 7249.

28 H. X. Gao, R. H. Wang, B. Twamley, M. A. Hiskey and J. M. Shreeve, Chem. Commun., 2006, 4007.

29 R. H. Wang, H. Y. Xu, Y. Guo, R. J. Sa and J. M. Shreeve, J. Am. Chem. Soc., 2010, 132, 11904.

30 A. A. Dippold, T. M. Klapötke and N. Winter, Eur. J. Inorg. Chem., 2012, 2012, 3474.

31 A. A. Dippold and T. M. Klapötke, J. Am. Chem. Soc., 2013, 135, 9931.

32 N. Fischer, D. Izsák, T. M. Klapötke, S. Rappenglück and J. Stierstorfer, Chem.-Eur. J., 2012, 18, 4051.

33 N. Fischer, L. Gao, T. M. Klapötke and J. Stierstorfer, Polyhedron, 2013, 51, 201.

34 D. Izsák, T. M. Klapötke and S. Reuter, Eur. J. Inorg. Chem., 2013, 2013, 5641.

35 S. Huber, D. Izsák, K. Karaghiosoff and S. Reuter, Propellants, Explos., Pyrotech., 2014, 39, 793.

36 D. Chand, D. A. Parrish and J. M. Shreeve, J. Mater. Chem. A, 2013, 1, 15383.

37 R. H. Wang, Y. Guo, Z. Zeng, B. Twamley and J. M. Shreeve, Chem.-Eur. J., 2009, 15, 2625.

38 L. X. Liang, K. Wang, C. M. Bian, L. M. Ling and Z. M. Zhou, Chem.-Eur. J., 2013, 19, 14902.

39 T. M. Klapötke, C. M. Sabaté and M. Rasp, J. Mater. Chem., 2009, 19, 2240.

40 Y. Guo, H. X. Gao, B. Twamley and J. M. Shreeve, Adv. Mater., 2007, 19, 2884.

41 M. Eberspächer, T. M. Klapötke and C. M. Sabaté, Helv. Chim. Acta, 2009, 92, 977. 
42 Y. H. Joo and J. M. Shreeve, Angew. Chem., Int. Ed., 2010, 49, 7320.

43 T. M. Klapötke, N. Mayr, J. Stierstorfer and M. Weyrauther, Chem.-Eur. J., 2014, 20, 1410.

44 J. H. Zhang and J. M. Shreeve, J. Am. Chem. Soc., 2014, 136, 4437.

45 Y. G. Huang, H. X. Gao, B. Twamley and J. M. Shreeve, Eur. J. Inorg. Chem., 2008, 2008, 2560.

46 T. Fendt, N. Fischer, T. M. Klapötke and J. Stierstorfer, Inorg. Chem., 2011, 50, 1447.

47 A. Hammerl, T. M. Klapötke, H. Nöth and M. Warchhold, Inorg. Chem., 2001, 40, 3570.

48 Y. H. Joo and J. M. Shreeve, Chem.-Eur. J., 2009, 15, 3198.

49 H. X. Gao, C. F. Ye, O. D. Gupta, J. C. Xiao, M. A. Hiskey, B. Twamley and J. M. Shreeve, Chem.-Eur. J., 2007, 13, 3853.

50 H. X. Gao, Y. G. Huang, C. F. Ye and B. Twamley, Chem.-Eur. J., 2008, 14, 5596.

51 T. M. Klapötke, J. Stierstorfer and A. Wallek, Chem. Mater., 2008, 20, 4519.

52 R. H. Wang, Y. Guo, Z. Zeng and J. M. Shreeve, Chem. Commun., 2009, 2697.

53 Y. G. Huang, Y. Q. Zhang and J. M. Shreeve, Chem. Eur. J., 2011, 17, 1538.

54 A. Hammerl, M. A. Hiskey, G. Holl, T. M. Klapötke, K. Polborn, J. Stierstorfer and J. M. Shreeve, Chem. Mater., 2005, 17, 3784.

55 Y. H. Joo and J. M. Shreeve, J. Am. Chem. Soc., 2010, 132, 15081.

56 D. Srinivas, V. D. Ghule, K. Muralidharan and H. D. B. Jenkins, Chem.-Asian J., 2013, 8, 1023.

57 Y. Tang, H. Gao, L. A. Mitchell, D. A. Parrish and J. M. Shreeve, Angew. Chem., Int. Ed., 2016, 55, 3200.

58 J. H. Zhang, S. Dharavath, L. A. Mitchell, D. A. Parrish and J. M. Shreeve, J. Am. Chem. Soc., 2016, 138, 7500.

59 Y. T. Gao, L. M. Zhao, F. Q. Pang, X. J. Qi, J. L. Huang and F. X. Chen, Chin. Chem. Lett., 2016, 27, 433.

60 P. Yin, C. L. He and J. M. Shreeve, J. Mater. Chem. A, 2016, 4, 1514.

61 P. Yin, C. L. He and J. M. Shreeve, Chem.-Eur. J, 2016, 22, 2108.

62 H. F. Huang, Y. M. Shi, Y. F. Liu and J. Yang, Chem.-Asian J., 2016, 11, 1688.

63 H. F. Huang, Y. M. Shi, Y. Li, Y. F. Liu and J. Yang, RSC Adv., 2016, 6, 64568.

64 Y. Li, H. Huang, X. Lin, R. Pan and J. Zhang, RSC Adv., 2016, 6, 54310 .

65 Y. Tang, C. He, L. A. Mitchell, D. A. Parrish and J. M. Shreeve, Chem.-Eur. J., 2016, 22, 11846.

66 Q. Wang, H. J. Lu, F. Q. Pang, J. L. Huang, F. D. Nie and F. X. Chen, RSC Adv., 2016, 6, 56827.

67 Z. B. Zhang, L. Yin, X. Yin and J. G. Zhang, Crystals, 2016, 6, 21. 68 C. L. He, Y. X. Tang, L. A. Mitchell, D. A. Parrish and J. M. Shreeve, J. Mater. Chem. A, 2016, 4, 8969.

69 Q. Q. Liu, B. Jin, R. F. Peng, Z. C. Guo, J. Zhao, Q. C. Zhang and Y. Shang, J. Mater. Chem. A, 2016, 4, 4971.

70 T. M. Klapötke, J. Stierstorfer, M. Weyrauther and T. G. Witkowski, Chem.-Eur. J., 2016, 22, 8619.
71 J. P. Zhu, S. H. Jin, L. Wan, C. Y. Zhang, L. J. Li, S. S. Chen and Q. H. Shu, Dalton Trans., 2016, 45, 3590.

72 T. M. Klapötke, C. Pflüger and M. W. Reintinger, Eur. J. Inorg. Chem., 2016, 2016, 138.

73 D. Izsk, T. M. Klaptke, F. H. Lutter and C. Pflüger, Ber. Dtsch. Chem. Ges., 2016, 2016, 1720.

74 V. Forquet, C. M. Sabate, G. Jacob, Y. Guelou, H. Delalu and C. Darwich, Chem.-Asian J., 2015, 10, 1668.

75 T. Fei, H. W. Cai, Y. Q. Zhang, L. Liu and S. J. Zhang, J. Energ. Mater., 2016, 34, 138.

76 G. Drake, T. Hawkins, A. Brand, L. Hall, M. Mckay, A. Vij and I. Ismail, Propellants, Explos., Pyrotech., 2003, 28, 174.

77 J. Aprawal, Prog. Energy Combust. Sci., 1998, 24, 1.

78 H. Xue, S. W. Arritt, B. Twamley and J. M. Shreeve, Inorg. Chem., 2004, 43, 7972.

79 Z. Zeng, R. H. Wang, B. Twamley, D. A. Parrish and J. M. Shreeve, Chem. Mater., 2008, 20, 6176.

80 G. Drake, G. Kaplan, L. Hall, T. Hawkins and J. Larue, J. Chem. Crystallogr., 2007, 37, 15.

81 Q. H. Lin, Y. C. Li, Y. Y. Li, Z. Wang, W. Liu, C. Qi and S. P. Pang, J. Mater. Chem., 2012, 22, 666.

82 J. T. Wu, J. G. Zhang, X. Yin, Z. Y. Cheng and C. X. Xu, New J. Chem., 2015, 39, 5265.

83 J. T. Wu, J. G. Zhang, X. Yin and K. Wu, Chem.-Asian J., 2015, 10, 1239-1244.

84 M. V. Denffer, T. M. Klapötke, G. Kramer, G. Spie $\beta$, J. M. Welch and G. Heeb, Propellants, Explos., Pyrotech., 2005, 30, 191.

85 H. Xue, Y. Gao, B. Twamley and J. M. Shreeve, Chem. Mater., 2005, 17, 191.

86 T. M. Klapötke, K. Karaghiosoff, P. Mayer, A. Penger and J. M. Welch, Propellants, Explos., Pyrotech., 2006, 31, 188.

87 K. Karaghiosoff, T. M. Klapötke, P. Mayer, C. M. Sabsté, A. Penger and J. M. Welch, Inorg. Chem., 2008, 47, 1007.

88 T. M. Klapötke and C. M. Sabaté, Z. Anorg. Allg. Chem., 2009, 635, 1812.

89 K. Karaghiosoff, T. M. Klapötke and C. M. Sabaté, Chem.Eur. J., 2009, 15, 1164.

90 T. M. Klapötke, P. Mayer, A. Schulz and J. J. Weigand, J. Am. Chem. Soc., 2005, 127, 2032.

91 T. M. Klapötke, C. M. Sabaté and J. M. Welch, Z. Anorg. Allg. Chem., 2008, 634, 857.

92 J. C. G. Ruiz, G. Holl, K. Karaghiosoff, T. M. Klapötke, K. Löhnwitz, P. Mayer, H. Nöth, K. Polborn, C. J. Rohbogner, M. Suter and J. J. Weigand, Inorg. Chem., 2005, 44, 4237.

93 G. H. Tao, Y. Guo, D. A. Parrish and J. M. Shreeve, J. Mater. Chem., 2010, 20, 2999.

94 T. M. Klapötke, D. G. Piercey and J. Stierstorfer, Eur. J. Inorg. Chem., 2012, 2012, 5694.

95 W. Ogihara, M. Yoshizawa and H. Ohno, Chem. Lett., 2004, 33, 1022.

96 A. R. Katrizky, S. Singh, K. Kostyantyn, J. D. Holbrey, M. Smiglak, W. M. Reichert and R. D. Rogers, Chem. Commun., 2005, 868.

97 H. Xue and J. M. Shreeve, Adv. Mater., 2005, 17, 2142. 
98 H. Xue, B. Twamley and J. M. Shreeve, J. Org. Chem., 2004, 69, 1397.

99 Y. R. Mirazei, B. Twamley and J. M. Shreeve, J. Org. Chem., 2002, 67, 9340.

100 H. X. Gao, C. F. Ye, R. W. Winter, G. L. Gard, M. E. Sitzmann and J. M. Shreeve, Eur. J. Inorg. Chem., 2006, 2006, 3221.

101 M. A. Romero, Org. Chem. Int., 2016, 2016, 4705809.

102 J. T. Wu, J. G. Zhang, X. Yin and T. L. Zhang, Z. Anorg. Allg. Chem., 2014, 640, 2544.

103 Q. H. Lin, Y. C. Li, C. Qi, W. Liu, Y. Wang and S. P. Pang, J. Mater. Chem. A, 2013, 1, 6776.

104 J. T. Wu, J. G. Zhang, X. Yin and L. Wu, New J. Chem., 2016, 40, 5414.

105 B. Wu, Z. X. Wang, H. W. Yang, Q. H. Lin, X. H. Ju, C. X. Lu and G. B. Cheng, New J. Chem., 2015, 39, 893.
106 T. M. Klapötke, F. Mieskes, J. Stierstorfer and M. Weyrauther, Propellants, Explos., Pyrotech., 2016, 41, 217.

107 Y. Gao, C. F. Ye, B. Twamley and J. M. Shreeve, Chem.-Eur. J., 2006, 12, 9010.

108 H. Xue, B. Twamley and J. M. Shreeve, Inorg. Chem., 2005, 44, 7009.

109 T. M. Klapötke, P. C. Schmid, S. Schnell and J. Stierstorfer, J. Mater. Chem. A, 2015, 3, 2658.

110 C. Qi, S. H. Li, Y. C. Li, Y. Wang, X. K. Chen and S. P. Pang, J. Mater. Chem., 2011, 21, 3221.

111 W. Liu, S. H. Li, Y. C. Li, Y. Z. Yang, Y. Yu and S. P. Pang, J. Mater. Chem. A, 2014, 2, 15978. 